\title{
Types of boredom and other learning activity emotions: A person-centred investigation of inter-individual data
}

\author{
Dirk Tempelaar $^{1}\left[\right.$ [ Alexandra Corina Niculescu ${ }^{2}$
}

Accepted: 26 August 2021 / Published online: 31 August 2021

(c) The Author(s) 2021

\begin{abstract}
Whether boredom is a unitary construct or if multiple types of boredom exist is a long-standing debate. Recent research has established the existence of boredom types based on frequency observations of boredom by experience sampling. This work tries to expand our understanding of boredom and replicate these previous findings by applying intensity observations of cross-sectional type for four discrete learning activity emotions: boredom, anxiety, hopelessness, and enjoyment. Latent class analysis based on activity emotion scores from 9863 first-year students of a business and economics program results in seven profiles. Five of these profiles allow a linear ordering from low to high control and value scores (the direct antecedents of emotions), low to high positive, and high to low negative emotions. Two profiles differ from this pattern: one 'high boredom' profile and one 'low boredom' profile. We next compare antecedent relationships of activity emotions at three different levels: inter-individual, inter-class or between classes, and intra-class or within classes. Some of these relationships are invariant for the choice of level of analysis, such as hopelessness. Other relationships, such as boredom, are highly variant: within-class relationships differ from inter-individual relationships. Indeed, our results confirm that boredom is not a unitary construct. The types of boredom found and their implications for educational practice are discussed and shared in this article.
\end{abstract}

Keywords Achievement emotions $\cdot$ Boredom $\cdot$ Person-centred modelling $\cdot$ Latent class analysis $\cdot$ Inter-individual analysis

\section{Introduction}

\section{Boredom among learning activity emotions}

'While studying this boring material, I spend my time thinking of how time stands still'... now read this statement again and reflect upon it for a moment. How many times did you feel bored while performing an activity that was supposed to be useful and enriching for your studies or your daily work? At some point in life, anyone could relate to this. However, the opening statement only describes an item

Dirk Tempelaar

D.Tempelaar@MaastrichtUniversity.nl

Alexandra Corina Niculescu

alexandra.niculescu@cemo.uio.no

1 Department of Quantitative Economics, Maastricht University, School of Business and Economics,

Tongersestraat 53, Maastricht 6211 LM, The Netherlands

2 Faculty of Educational Sciences, Centre for Educational Measurement, University of Oslo, Forskningsparken, Gaustadalléen 21, Oslo, Norway used in a scale (from the Achievement Emotions Questionnaire by Pekrun et al., 2011) designed to measure boredom related to studying and learning activities. What makes it concerning is that boredom, described as a 'silent' (Goetz et al., 2014) learning emotion is yet frequently experienced (Pekrun et al., 2010) in achievement settings. Beyond how often boredom is encountered, there is another issue related to how strong boredom is experienced, its intensity. Indeed, findings from university settings show boredom mean levels are above neutral levels (Goetz \& Hall, 2014). Even more, over the past years (from 2008 to 2017), boredom in secondary school U.S. students indicates an increasing trend where for boys and girls altogether, elevated levels of boredom seem to pick in the 10th grade (Weybright et al., 2020). As recent research warns against the negative impact of boredom on health-related quality of life in adolescence (Schwartze et al., 2021), exploring boredom in educational settings comes across as a necessity still not sufficiently investigated beyond this vulnerable period (Loukidou et al., 2009).

Going back to the fact that at some point in life, everyone experiences boredom - be it more or less frequently and 
intensely, the question remains if this feels the same for all individuals or if there are different experiences or types of boredom. Put differently, what is more interesting to investigate is if boredom is a unitary construct or rather a heterogeneous one. We are therefore interested in understanding boredom experienced in achievement contexts.

The next section will explain boredom more generally, covering its operational definition and its underlying conceptual dimensions in light of various theoretical accounts. This is done to clarify to what extent boredom is a unitary construct or rather a heterogeneous one.

\section{Models of boredom and the CVTAE}

Overall, the subjective experience of being in a state, often regarded as unwanted and unpleasant (Eastwood et al., 2012), associated with a perceived slow passage of time, behavioural and cognitive disengagement (Goetz $\&$ Hall, 2014) and a particular difficulty to stay attentive (Elpidorou, 2018b), which prompts to taking action to escape the present moment (Westgate $\&$ Wilson, 2018) is regarded as state boredom. More generally, state boredom was classified according to different models. According to Westgate and Wilson (2018), these models can be organized into three groups. First, there are the environmental theories that explain boredom as a result of the external context, where the emphasis is put on either insufficient external stimulation from the environment (Goetz et al., 2006, 2014) or the effect of external constraints (Pekrun, 2006; Goetz et al., 2014). Second, attentional theories of boredom accentuate the role of internal psychological processes and propose that boredom results from a failure in attention (Eastwood et al., 2012). The third group includes the functional theories of boredom which propose a different aspect of boredom by looking at its underlying purpose in terms of either (serving) goals, (avoiding) opportunity cost or (finding) meaning. In this last approach, boredom is described as a functional emotion because it both signals a need for change and serves a regulatory role with the potential to contribute to the individual's wellbeing (Elpidorou, 2018a,b). In addition to these three sets of models, Westgate and Wilson (2018) propose a fourth: the Meaning and Attention Components (MAC) Model of Boredom. MAC encompasses the previous views on boredom by assuming that the emotion is experienced when individuals are also 'unable or unwilling' (Westgate \& Wilson, 2018, p. 693) to engage with a certain task. In consequence, MAC proposes that different types of boredom can emerge based on the triggers of boredom (the lack of meaning or the attention deficit). It is important to note that relevant research following these models, still debates upon one dimension of boredom: its arousal or activation dimension. Findings have shown that state boredom can be defined in terms of a state of low arousal (Mercer \& Eastwood, 2010; van Tilburg \& Igou, 2016), a state of high arousal (Ohsuga et al., 2001), or a state of both, mixed high and low, accounting even for the flexibility of arousal (Eastwood et al., 2012; Goetz et al., 2014; Mills \& Christoff, 2018; Elpidorou, 2020). For these conflicting accounts, Goetz and Hall (2014) propose two possible explanations: on the one hand, it is argued that the arousal concept itself might be multidimensional; on the other hand, it is the possibility of multiple types of boredom. While some authors have argued against this last possibility on the basis of associated arousal levels (Elpidorou, 2020), the problem of heterogeneity for boredom remains a long standing debate (Goetz et al., 2014; Goetz \& Frenzel, 2006; Westgate \& Wilson, 2018; Elpidorou, 2020) which dates back to the renowned work of Fenichel (1951) and still remains to be settled.

So how is boredom conceptualized in an academic context? When experienced in such situations, it is referred to as academic boredom (Pekrun et al., 2011), an emotional state which can occur in all instances encountered in academic settings: when attending lectures or during classes (class boredom), while taking an exam (test boredom) and finally, when preparing homework, studying or performing any learning activity (learning boredom). From this perspective, boredom is seen as an activity emotion (Pekrun et al., 2010). Furthermore, boredom was conceptualized in terms of the factors that explain this emotion in the context of a performed activity by how is the task at hand perceived (Pekrun et al., 2010; van Hooft \& van Hooff, 2018). To conclude on what boredom is, it is also relevant to clarify what boredom is not, or more precisely, how it relates to other emotions in the same learning context. Previous studies show that academic boredom is positively related to other negative emotions and negatively related to positive emotions (Goetz et al., 2006; Pekrun et al., 2011; Niculescu et al., 2015). The strength of these relations, medium in size, points to the fact that boredom neither overlaps with other negative emotions nor it merely represents the absence of positive emotions (Goetz \& Hall, 2014).

The Control-Value Theory of Achievement Emotions (CVTAE; Pekrun, 2006) represents a framework addressing the antecedents and consequences of achievement emotions related to achievement activities and achievement outcomes. According to CVTAE, achievement emotions are described over two dimensions, valence and arousal; in the case of boredom, the valence is negative, and the arousal is deactivating (Pekrun et al., 2010). Boredom emerges from beliefs about a low capacity to influence outcomes (Pekrun, 2000; Frenzel et al., 2007), generally referred to as control appraisals (Pekrun et al., 2002). As proximal antecedents of boredom and other achievement emotions, control and value are themselves predicted by distal antecedents of both individual 
and task-related learning environment types (Pekrun, 2006). Gender and achievement goal setting belong to the distal antecedents of individual type (Pekrun, 2006).

Most research into achievement emotions and their antecedents operationalize emotions using a measure of the intensity of the emotional sentiment. In studies into the existence of boredom types, Goetz et al., $(2014,2016)$ applied person-oriented modelling approaches to the frequency of boredom experiences, resulting in five boredom types: the first type, 'indifferent' boredom, was characterized by low arousal and a rather positive valence; the second type, 'calibrating' boredom, by higher arousal (than the indifferent boredom) and a rather negative valence; the third type, 'searching' boredom was marked by higher arousal and more negative valence than the calibrating boredom; the fourth type, 'reactant' boredom was identified by the highest level of arousal and negative valence when compared to all previous types. Finally, the fifth boredom - an unexpected finding in the study by Goetz et al. (2014), was distinguished from the other four types by a very low level of arousal and high negative valence; accordingly, this type was referred to as 'apathetic' boredom. More precisely, the first four boredom types were linearly structured along valence and arousal dimensions, the fifth type, apathetic boredom, falling outside this linear relationship. Such conceptualization of boredom implies that the meaning of the emotional experience is in fact, multifaceted. In other words, there is not one subjective experience of emotion but more: when feeling indifferently bored, there is a sense of relaxation, of being withdrawn from action; when experiencing calibrating boredom, there is a certain receptiveness to change; in the state of searching boredom, a perceived restlessness and a pursuit for change become apparent; during reactant boredom, a high degree of restlessness and the motivation to search for alternative situations than the present state are the focus; finally, feeling apathetically bored is a particularly unpleasant emotion, in the same range of experiences as hopelessness and depression (Goetz \& Hall, 2014). Most notably, it was suggested that different experiences of boredom, or multiple types, shape further reactions based on the boredom's underlying antecedents (Westgate \& Wilson, 2018). As such, this is relevant and can impact different outcomes over the academic context, like learning and achievement.

According to Krannich et al., (2019, p. 208), 'The most common antecedents of boredom include individuals' states of being over- and under-challenged'. The explanation rests on the CVTAE: boredom occurs when a lack of control goes together with a lack of value. This is the case when the learning task is viewed as unimportant in combination with being either too demanding or too less demanding (Pekrun et al., 2010; Daniels et al., 2015). Recent research applying cross-sectional analysis and experience sampling by Chan et al. (2018) confirms the role of lack of challenge and meaning where state boredom is associated with situational meaninglessness.

\section{Inter-individual, intra-individual and person-centred approaches}

The debate upon the merits of inter-individual analyses versus intra-individual analyses in psychological research is highly visible within the domain of learning emotions. Early studies applying intra-individual analyses of data collected by experience sampling have been around for two decades, primarily studies of learning boredom by Thomas Goetz and coauthors (Goetz et al., 2006, 2014, 2019). Their methodological choices of experience sampling followed by intra-individual or within-person analyses found their way to other areas of achievement emotions, such as the relations between achievement goals and achievement emotions (Goetz et al., 2016; Linnenbrink-Garcia et al., 2016) or the relations between epistemic emotions, achievement emotions, and knowledge exploration (Vogl et al., 2019).

The plea for greater application of within-person, intraindividual research in educational psychology is derived from Molenaar's contribution to system theory (2004; Molenaar \& Campbell, 2009; Voelkle et al., 2014). That contribution focuses on the ergodic theorems of dynamic systems. Ergodicity addresses the question under what conditions the analysis of inter-individual or between-person variation results in the same outcomes as the analysis of intra-individual or within-person variation. The answer is given by the two ergodic conditions: (1) homogeneity, each subject in the population obeys the same statistical model, and (2) stationarity, that statistical model is constant over time (Molenaar, 2004; Molenaar \& Campbell, 2009). The second condition refers to dynamic systems, such as developmental systems or psychological processes (Molenaar, 2004). This dynamical aspect is manifest in examples covered in Murayama et al. (2017) as well as the explicit reference to the process nature. The authors caution against applying intra-individual focus analysis to between-person covariation data, thereby emphasizing the specificity of each approach.

Educational studies do not always focus on processes; the question of whether boredom types exist has no dynamical dimension. If one wishes to derive a typology and measurements are of cross-sectional nature, what do ergodic conditions amount to? The stationarity condition is irrelevant, and therefore ergodicity comes down to homogeneity.

According to Howard and Hoffman (2018), both interindividual analysis (termed variable-centred approaches) and intra-individual analysis (termed person-specific approaches) are the poles of a continuum of methodological approaches. They characterize these methodological approaches with two attributes: specificity and parsimony. In that continuum ranging from relative parsimony, the variable-centred pole, 
to relative richness, the person-specific pole, Howard and Hoffman (2018) position a third approach in the middle: the person-centred approach. In this approach, unobserved heterogeneity in the population is acknowledged and solved by classifying subjects into homogeneous subpopulations. The analysis aims to understand relations with antecedents and consequences on the subpopulation level, just as one would do in the variable-centred approach when the population is homogeneous. Person-centred approaches fall into the middle of the continuum: their solutions are richer but less parsimonious than variable-centred outcomes, describing subpopulations by different models, but are less rich and more parsimonious than person-specific solutions that create models for each subject.

Our analysis aims to investigate if the several boredom types that result from researching the frequency of boredom experiences (Goetz et al., 2014, 2016) can be replicated in researching the intensity of boredom experiences, as in survey-based research. Our cross-sectional data do not permit an intra-individual or person-specific type of analysis. However, the Howard and Hoffman (2018) scheme would not even suggest doing so, where we wish to derive a typology and its antecedents, which is not a developmental process. However, there is a strong suspicion of heterogeneity, suggesting a breakdown of the other ergodic condition. For these reasons, a person-centred modelling approach is preferred. Where stationarity is not relevant, but homogeneity is, two levels of analysis are relevant: inter-class or between classes versus intra-class or within classes. This implies three levels of analysis of variation: inter-individual variation, decomposed into inter-class and intra-class variation.

\section{Aims and research questions}

In our authentic learning context-based study, we investigate the existence of typologies for boredom; this is our main aim to figure out the internal validity of the boredom types.

The typology for other emotions (anxiety, hopelessness and enjoyment) is examined to establish the external validity of the boredom types. In line with Goetz et al., (2014, 2016), we expect to establish multiple types. Likewise, we also expect the boredom types to differ from the other emotions. Subsequent aims investigate how such typology impacts antecedent relationships of emotions, such as the over-and under-challenge hypothesis (Pekrun et al., 2010). Finally, we aim to inspect how such typology relates to trait versus state characteristics of emotions.

In this study, we follow the Goetz et al. studies by taking the person-oriented approach of latent class modelling but base this on emotion intensity data, gathered by using the AEQ instrument (Pekrun et al., 2011). This choice allows the reformulating of the main goals of the current paper. Goetz et al., $(2014,2016)$ derive the existence of boredom types from emotion frequency data. Our first research question is: (RQ1) To what extent do more conventional intensity data also support the existence of multiple types? Is this a generic feature, irrespective of the operationalization of boredom, or a characteristic of the experience-sampling method directed at the frequency of emotional sentiments? Our second research question (RQ2) addresses the invariance of relationships between activity emotions or lack thereof: how different are intra-class and inter-class relations? Third (RQ3), we investigate invariance over contexts: what emotions are best characterized as dispositions or context-dependent? The fourth research question (RQ4) addresses boredom associated with a lack of challenge and meaning. The last and fifth research question asks: (RQ5) what is the role of distal antecedents concerning the activity emotions?

In terms of operationalization, we applied latent class modelling to all facets of learning activity emotions: boredom, anxiety, hopelessness, and enjoyment, rather than boredom in isolation. Moreover, we did so in a learning context, having the full range of strong under-challenge to strong over-challenge conditions. Since all achievement emotions in this study are of learning activity type, we will address them as activity emotions.

\section{Method}

In educational research, tests of hypothesized relationships are typically based on variable-centred modelling approaches, such as regression, factor analysis, or structural equation modelling applied to inter-individual variation in the full sample (Marsh et al., 2009; Masyn, 2013; Morin et al., 2018; Howard \& Hoffman, 2018). This approach is based on the strict assumption "that all individuals from a sample are drawn from a single population for which a single set of "averaged" parameters can be estimated" (Morin et al., 2018, p. 804). When homogeneity lacks, personcentred modelling approaches (Masyn, 2013; Morin et al., 2018; Howard \& Hoffman, 2018) have the goal to group individuals, such that people within each category are similar to each other and different from individuals in other categories. These approaches "consider the possibility that the sample might include multiple subpopulations characterized by different sets of parameters" (Morin et al., 2018, p. 804). Since research questions are often formulated at the variable level, heterogeneity implies adopting a two-step approach: start with a person-centred approach to decompose a heterogeneous sample into homogeneous clusters or classes, and continue with a variable-centred approach based on the homogeneous sub-samples (Marsh et al., 2009; Morin et al., 2018). Our study decomposes the heterogeneous sample into (more) homogeneous subsamples based on Latent Class Analysis (LCA), applying MPlus, vs. 8.4. 


\section{Participants and educational context}

Participants were first-year students of a business and economics school in the south of the Netherlands entering the program in the ten most recent cohorts: 2010/2011 up to 2019/2020. These programs deviate from mainstream, European university education in two ways: student-centred instruction known as problem-based learning (PBL), and a strong international orientation: the programs mainly attract international students. Among the 9863 freshmen in this study, $40 \%$ are female, $60 \%$ male. Most students enter the program directly after finishing high school where the typical age range is $18-20$ years. Data were collected in an introductory module on mathematics and statistics, the first module of the program.

Prior education differs by nationality and mathematical track. Most national educational systems differentiate three tracks: preparing for arts and humanities, social sciences, and sciences. The second level is required for students in our programs, but $34 \%$ was educated at the highest level (indicated MathMajor). The diversity of students' prior education and prior knowledge creates diversity in the challenges students face following the module and is expected to result in diverse learning activity emotions.

Problem-based learning takes place in small tutorial groups of 14 students. Online learning opportunities were added primarily to support less-prepared students with a broad range of learning tools, creating a blended environment. The face-to-face component focuses on collaborative problem solving of open-ended problems. The 'flipped classroom' type of instruction resulting from this setup is documented in Williams et al. (2016).

The application of dispositional learning analytics further scaffolds student learning. Learning analytics (Shum \& Crick, 2012) aims to provide the student with learning feedback based on trace data derived from students' use of digital learning environments. Dispositional learning analytics (Tempelaar et al., 2015, 2018) adds learning dispositions measured through self-report surveys as another data source. Beyond achievement emotions, learning dispositions collected include learning attitudes related to mathematics and statistics, epistemic learning emotions (in the most recent six cohorts), and other learner data collected for dispositional learning analytics but not used in this study.

\section{Materials}

\section{Achievement and epistemic emotions}

The Control-Value Theory of Achievement Emotions (CVTAE, Pekrun, 2006) postulates that achievement emotions differ in valence, focus, and activation. From the Achievement Emotions Questionnaire (AEQ, Pekrun et al.,
2011), an instrument based on CVTAE, we selected from the eight scales included in the AEQ the four emotion scales that are most strongly related to academic performance: positive activating Enjoyment, negative activating Anxiety, and negative deactivating Boredom and Hopelessness. Given the primacy of independent, self-regulated learning in the PBL system, the learning-related versions of the scales were applied, rather than the class- or test-related versions. Where these achievement aspects of emotions focus on doing a learning activity, epistemic emotions relate to the cognitive aspects of the task itself (Pekrun, 2012). Epistemic emotions were measured with the Epistemic Emotion Scales (EES, Pekrun et al., 2017) and included Surprise, Curiosity, Confusion, Anxiety, Frustration, Enjoyment, and Boredom. AcademicControl, measured with the perceived Academic control scale of Perry et al. (2001), is included as one of the proximal antecedents of activity emotions. In this study, epistemic emotions are regarded as distal antecedents of achievement emotions.

\section{Attitudes towards learning}

To supplement the proximal control antecedent with the value facet, we applied an extended version of the Survey of Attitudes Toward Statistics (SATS, Tempelaar, et al., 2007). Based on the expectancy-value theory (Wigfield \& Eccles, 2000), the instrument counts six quantitative methodsrelated attitudes toward learning. Two of these scales were applied to represent extrinsic and intrinsic facets of valuing learning mathematics and statistics: Utility-value, students' attitudes about the usefulness, relevance and worth in their life, and Intrinsic-value, students' level of individual interest.

\section{Student background data}

Gender (Female) and prior mathematics education (MathMajor) are two indicator variables that account for demographic factors.

\section{Procedure}

Students followed two modules in the first eight weeks of their program, one being an integrated course on mathematics and statistics. Students complete self-report questionnaires on learning dispositions in the first and middle week as part of a student project for statistics. Since these were the first weeks in university, responses to learning disposition instruments administered at the start of the module, such as epistemic emotions, typically reflect learning dispositions in high school. Halfway through the term, students completed the questionnaires on activity emotions and learning attitudes. This timing ascertains that students were sufficiently familiarized with the new learning environment. 
The naturalistic setting impacts the nature of the learning emotions measurements. Our authentic context of independent student learning prevented the explicit connection of activity emotions from doing a particular learning activity. Instead, students were asked to respond to the emotion survey on a retrospective account in the context of individual problem-solving activities they did that week.

Ethics approval was obtained by the Ethical Review Committee of Maastricht University (ERCIC_044_14_07). Participants in the study provided informed consent to use personal data for the generation of learning feedback for the improvement of instruction and educational research.

\section{Statistical analyses}

Nonlinear relationships between activity emotions and proximal antecedents were investigated with hierarchical regression models, allowing for linear, quadratic, and cubic terms. To minimize collinearity, the AcademicControl variable was de-meaned.

Person-oriented modelling of activity emotions was performed with latent-class analysis based on all four activity emotions scores. In deciding upon the number of latent classes, both substantial criteria and fit and information criteria were applied (Howard \& Hoffman, 2018).

\section{Results}

This results section starts with an analysis of descriptive statistics of activity emotions, followed by the principal inferential analysis: the estimation of the latent class model to answer the first research question. In the following sections, we apply different descriptive methods to answer the remaining research questions.

\section{Descriptive statistics of learning activity emotions}

Table 1 contains descriptive statistics of learning activity emotions and proximal antecedents: means, standard deviations, skewness, kurtosis, sample reliability (Cronbach alpha) and correlations (full correlation matrix in Statistical Appendix, Table SA1). No measure signals any deviation from standard criteria for univariate analysis (Kline, 2016). Measures collected in ten cohorts, Fig. 1 describes the evolvement of means of activity emotions in consecutive academic years. Enjoyment means fluctuate just above the neutral anchor of four; Anxiety means fluctuate just below the neutral score. Boredom and Hopelessness scores are below the neutral score, fluctuating around three. However, fluctuations are limited in size, and in all learning activity emotions, time explains less than five per cent of the variation in means over academic years, suggesting stability in the experience of learning activity emotions.

\section{Latent class analysis and the description of the 7-class solution}

To investigate the first research question, latent class analyses based on Anxiety, Boredom, Hopelessness, and Enjoyment scores are run for one to twelve classes. The decision for the number of latent classes is based on statistical criteria: fit and information indices, and substantive considerations, the interpretation of latent classes.

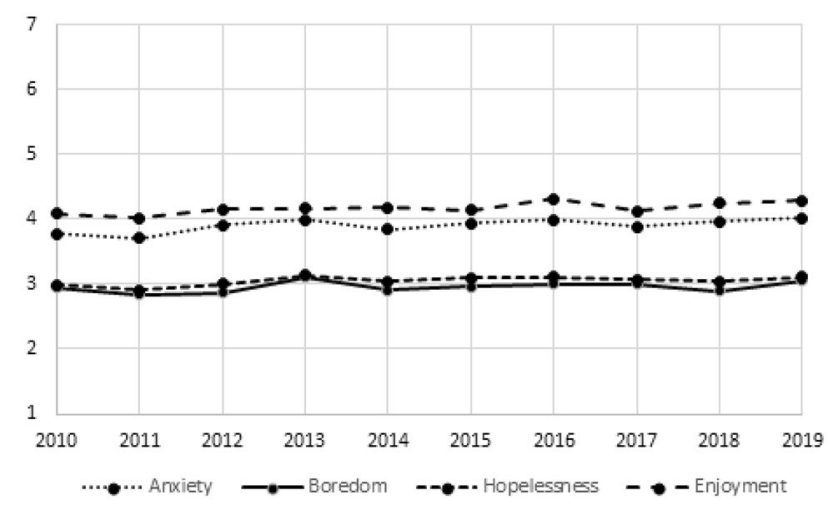

Fig. 1 Mean levels of activity emotions anxiety, boredom, hopelessness, and enjoyment over time

Table 1 Descriptive statistics of activity emotions and proximal antecedents

\begin{tabular}{lcccccccccccc}
\hline Emotion & Mean & SD & Kurto-sis & Skewness & Reliability & 1 & 2 & 3 & 4 & 5 & 6 \\
\hline 1. Anxiety & 3.909 & 1.172 & -0.432 & -0.104 & 0.918 & 1.00 & & & & & \\
2. Boredom & 2.964 & 1.124 & -0.092 & 0.529 & 0.934 & 0.375 & 1.00 & & & \\
3. Hopelessn & 3.058 & 1.220 & -0.310 & 0.453 & 0.945 & 0.827 & 0.528 & 1.00 & & \\
4. Enjoyment & 4.176 & 0.904 & 0.064 & -0.164 & 0.849 & -0.302 & -0.499 & -0.442 & 1.00 & \\
5. AcadControl & 5.164 & 0.854 & 0.010 & -0.428 & 0.789 & -0.552 & -0.342 & -0.685 & 0.341 & 1.00 & \\
6. Intr-value & 5.218 & 1.050 & 0.634 & -0.755 & 0.840 & -0.221 & -0.284 & -0.331 & 0.276 & 0.302 & 1.00 \\
7. Util-value & 5.243 & 0.834 & 0.093 & -0.401 & 0.787 & -0.162 & -0.371 & -0.264 & 0.449 & 0.227 & 0.549 & 1.00 \\
\hline
\end{tabular}

Scales based on Likert $1-7$ type items; $p$ value $<0.001$ for all correlations 
Statistical criteria to compare LCA solutions with a different number of classes are in Table SA2 (Statistical Appendix). The fit criteria of Log-likelihood, BIC, adjusted BIC, and AIC all demonstrate a continuous decrease when adding classes with increments getting smaller. What is a common LCA outcome: "most of the statistical fit criteria indicate better fit as more profiles are added to the model" (Howard \& Hoffman, 2018, p. 858). Entropy measures as information criterion fluctuate around 0.8. BLRT and LMR tests p-values provide the most apparent signals: up to seven classes, each additional class improves fit significantly, with $\mathrm{p}$ values below 0.020 , but the 8 -class does not: the p-values for BLRT and LMR are both larger than 0.200. The 9-class and 10-class solutions provide a better fit than the 8-class solution again, but from 11 classes on, fit does not improve anymore. BLRT and LMR log-likehoods coincide with model log-likelihoods in all LCS solutions, indicating the stability of these solutions. See Table SA2 (Statistical Appendix).

The main objective of the latent class analysis is to investigate the existence of exceptional classes standing out from the linear ordering induced by the control-value framework, as the apathetic boredom class in the Goetz et al. (2014) study. That objective feeds our substantive argumentation: we wish to include any stable class that escapes the CVTAE based ordering. This substantive argument is best illustrated graphically: Fig. 2. Latent class solutions with two to five latent classes generate profiles that differ quantitatively but not qualitatively: they adhere to the linear ordering. Increasing levels of Boredom go with increasing levels of Anxiety and Hopelessness, decreasing levels of Enjoyment, and, in line with CVTAE, decreasing levels of AcademicControl. The first panel of Fig. 2 demonstrates Boredom class means having a nearly perfect, negative linear relationship with AcademicControl class means. Inter-class correlations of Boredom and AcademicControl exceed 0.99. The 6-class LCA solution is the first with a qualitatively different profile: a class with relatively high Boredom levels (Fig. 2, second panel). This class shares properties of the apathetic boredom type (Goetz et al., 2014, 2016). The 7-class LCA solution adds an opposite qualitatively different class, with relatively low Boredom levels (Fig. 2, third panel). Other classes in the 6-class and 7-class solutions still obey the nearly perfect linear relationship. Adding more classes does not further enrich the type of profiles: it brings additional classes in line with above mentioned three patterns. The 10-class solution (Fig. 2, right panel) serves as an example to illustrate the existence of three class types: linearly ordered, high boredom type, and low boredom type. Based on the substantive argument of including the full typology of classes, class solutions with at least seven classes are preferred.

An additional requirement to the substantive argument is, according to Morin (2016), demonstrating the meaningfulness of each class. We interpreted this requirement that, amongst others, meaningful explanations can be provided on how multiple high boredom classes differ and how multiple low boredom classes, as visible in the 10-class solution, differ. However, a meaningful explanation of class differences is missing: additional exceptional classes are generated by splitting the single exceptional classes visible in the 7-class solution without a clear and interpretable demarcation between the split classes.

Statistical and substantial arguments taken together, the 7-class LCA solution was preferred. Increasing the number of latent classes beyond seven has mixed but small impacts of statistical criteria of fit. From a substantive point of view, the 7-class solution includes the full typology of linearly ordered, high-boredom, and low-boredom class types that characterizes all LCA solutions beyond seven classes. The stability of the finding of this typology answers our first research question: we indeed find a typology that shares the characteristics of the typology found in Goetz et al., (2014, 2016) and, on top of that, includes the mirror case of apathetic boredom. Amongst all higher-order LCA solutions, we
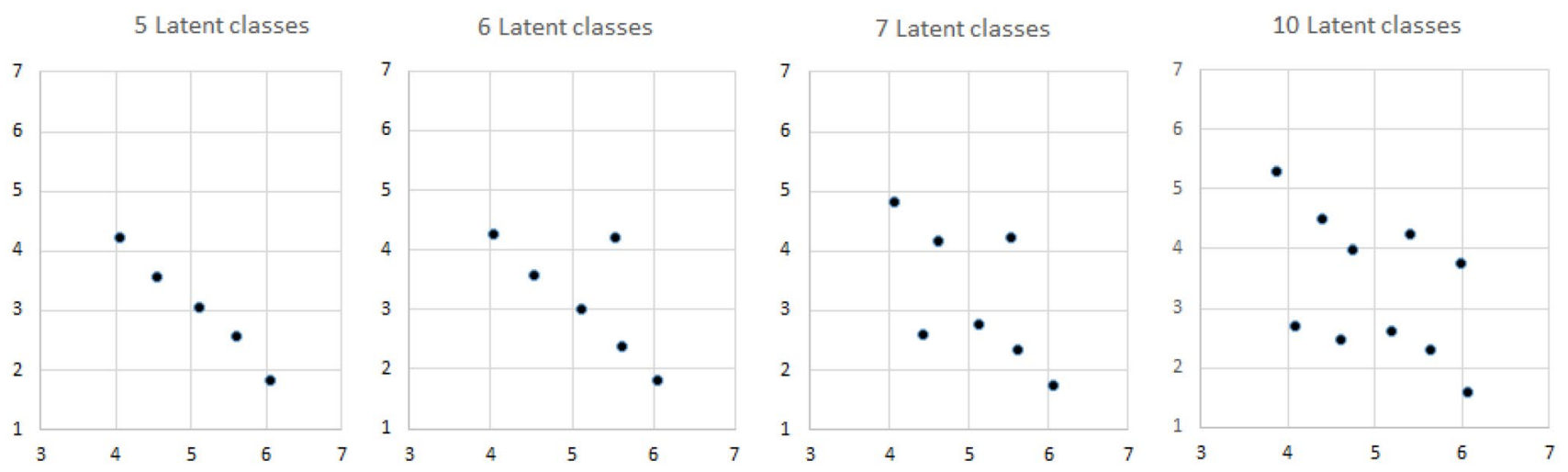

Fig. 2 Latent class means of boredom, vertical axis, against academiccontrol, horizontal axis, for latent class solutions with five, six, seven, and ten latent classes 
prefer the 7-class solution as the most parsimonious one for reasons of a meaningful interpretation of class differences.

Tables SA3 to SA9 (Statistical Appendix) provide correlation matrices for the seven latent classes.

The 7-class solution of the LCA of emotions Anxiety, Boredom, Hopelessness, and Enjoyment is best characterized by latent means of activity emotions and proximal antecedents: Table 2. Levels of Academic control order latent classes. The class with relatively high levels of Boredom is labelled ClassHigh, the class with relatively low levels of Boredom as ClassLow, the other classes as Class1 to Class5.

Three large classes are the non-extreme classes within the negative linear relationship between AcademicControl and Boredom: Class2, Class3, and Class4. The two classes at the poles of this linear relationship are smaller, especially Class1, having the lowest AcademicControl levels. All classes have mean AcademicControl levels above the neutral anchor: in general, students perceive being in control. The two deviant classes are relatively small.

The deviant characteristics of ClassHigh and ClassLow extend to the Enjoyment emotion. See Fig. 3, where the four panels depict the relationship between AcademicControl and activity emotions on class level, including error bounds. High Boredom-scores in ClassHigh go together with low Enjoyment-scores. Anxiety and Hopelessness scores are in line with the corresponding AcademicControl levels. ClassLow does not share that characteristic: Enjoyment levels are only fractionally higher.

Valuing of learning, the second proximal antecedent has Intrinsic and Utility-values as facets. Figure 4 depicts the relationship between Utility-value and emotions on the class level. The two deviant classes demonstrate nearly equal mean Utility-value scores. Relationships are linear: increasing for Enjoyment, decreasing for Boredom, Anxiety, and Hopelessness. Deviations from this linear pattern are less strong for Boredom and Enjoyment, stronger for Anxiety and Hopelessness. ClassHigh students distinguish by low Anxiety and low Hopelessness, relative to Utility-value levels. ClassLow students face relatively high levels of Anxiety and Hopelessness.

Intrinsic-value scores in ClassHigh and ClassLow are more differentiated than Utility-value scores; other observations for the Utility-value case are repeated for the Intrinsicvalue case. Concerning Boredom and Enjoyment, ClassHigh and ClassLow satisfy the linear relationship amongst all classes that Boredom decreases and Enjoyment increases with Intrinsic-value. Deviant behaviours are found for Anxiety and Hopelessness: students in ClassHigh have low Anxiety and Hopelessness levels relative to Intrinsic-value, the opposite being the case for ClassLow students: see Fig. 5 .
Table 2 Class size and latent class means of activity emotions and proximal antecedents

\begin{tabular}{lllllllll}
\hline & Total & Class1 & Class-Low & Class2 & Class3 & Class-High & Class4 & Class5 \\
\hline Class size & 9863 & 468 & 839 & 1748 & 2706 & 543 & 2603 & 956 \\
Anxiety & 3.91 & 5.84 & 5.43 & 4.59 & 4.27 & 2.96 & 3.15 & 1.95 \\
Boredom & 2.96 & 4.83 & 2.61 & 4.15 & 2.76 & 4.22 & 2.33 & 1.76 \\
Hopelessness & 3.06 & 5.67 & 4.70 & 4.08 & 3.12 & 2.37 & 2.10 & 1.30 \\
Enjoyment & 4.18 & 3.11 & 3.85 & 3.67 & 4.28 & 3.22 & 4.61 & 4.98 \\
AcademicControl & 5.16 & 4.06 & 4.42 & 4.62 & 5.11 & 5.52 & 5.62 & 6.05 \\
Intrinsic-value & 5.22 & 4.48 & 5.19 & 4.76 & 5.29 & 4.55 & 5.51 & 5.77 \\
Utility-value & 5.24 & 4.66 & 5.13 & 4.91 & 5.23 & 5.11 & 5.47 & 5.73 \\
\hline
\end{tabular}
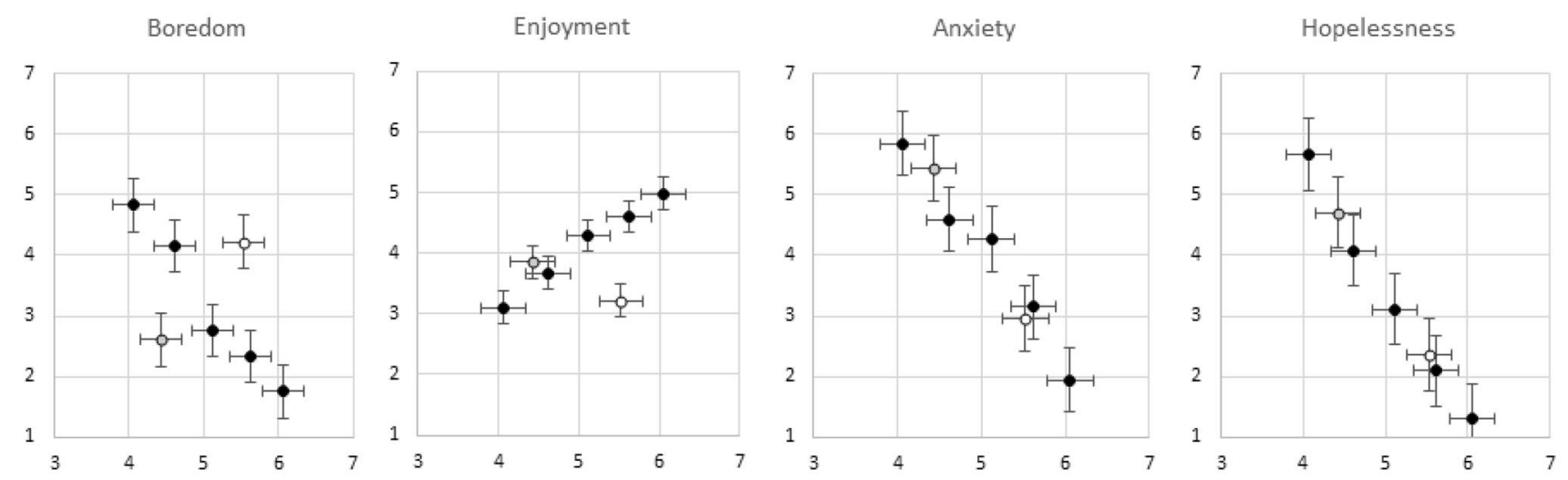

Fig. 3 Latent class means of activity emotions, vertical axis, against academiccontrol, horizontal axis. Class1 to Class5 with black marker, ClassHigh with white marker, ClassLow with grey marker. Error bounds added 

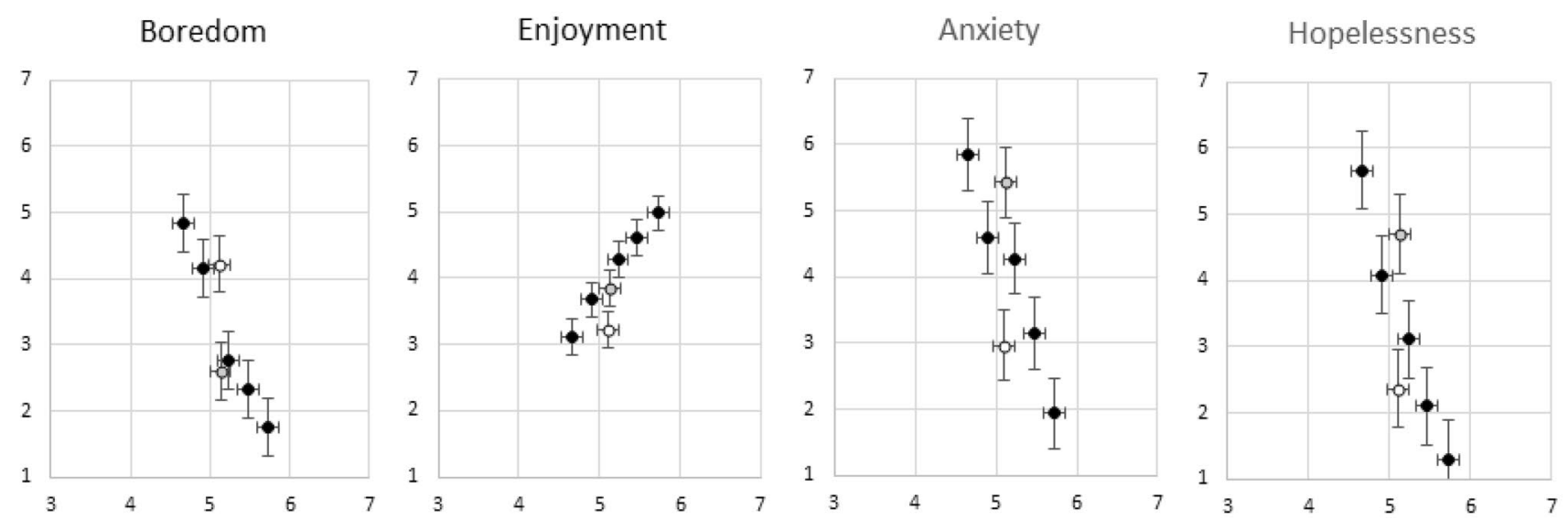

Fig. 4 Latent class means of activity emotions, vertical axis, against utility-value, horizontal axis. Class1 to Class5 with black marker, ClassHigh with white marker, ClassLow with grey marker. Error bounds added
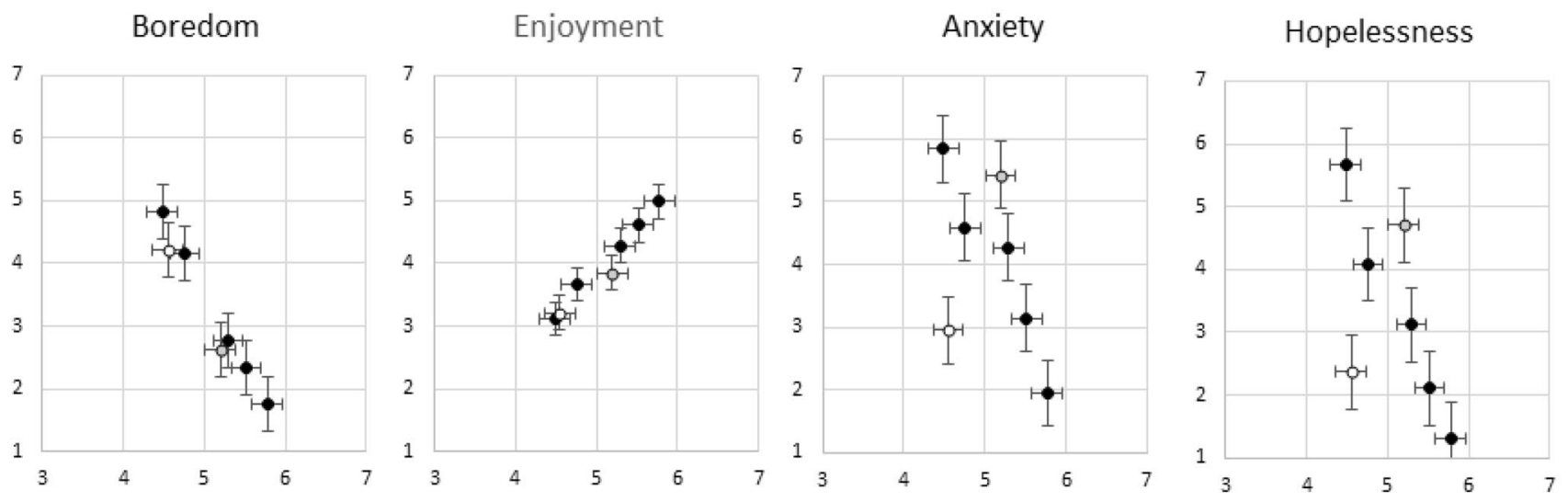

Fig. 5 Latent class means of activity emotions, vertical axis, against intrinsic-value, horizontal axis. Class1 to Class5 with black marker, ClassHigh with white marker, ClassLow with grey marker. Error bounds added

Classification probabilities for the most likely latent class membership (column) by latent class (row) are in Table SA10 (Statistical Appendix). They indicate that Class3 and Class 4 have more in common with each other than with ClassHigh, although AcademicControl in ClassHigh is in between those two classes.

\section{Inter-individual correlations at sample and class level}

To answer the second research question regarding the invariance of relationships of activity emotions, correlations of activity emotions and proximal antecedents at overall and class levels are contained in Table SA11 (Statistical Appendix), where each row represents one bivariate relationship. Full sample outcomes in the first column are in line with empirical research on inter-individual relationships of activity emotions and proximal antecedents, as predicted by
CVTAE: the sign of the correlation between two activity emotions is determined by the valence of both emotions that dominates the arousal dimension, and proximal antecedents relate positively to positive emotions, negatively to negative emotions. The other columns contain inter-individual correlations within classes. The general pattern is that, in absolute size, correlations within classes are smaller than full sample correlations. Beyond that pattern, remarkable differences are present in full sample and class correlations. For example, Anxiety and Boredom, two negative emotions, are positively related in the full sample, but negatively related in several classes, except ClassHigh and ClassLow. With the impact of the valence dimension being partly absorbed by class differences, the analysis at the class level gives more space for the activation dimension to become visible: the deactivating nature of Boredom and the activating nature of Anxiety. The correlation between Boredom and Enjoyment is mostly negative, except again ClassHigh, ClassLow, and also Class1. 
The negative full sample correlation between Anxiety and Enjoyment does not show up in any class.

AcademicControl is inversely related to Boredom in the full sample, but that relationship vanishes or even turns positive in all classes. It is only the relationship between control and Hopelessness that consistently carries over from full sample to classes. Intrinsic-value relates to Boredom and Enjoyment stronger than to Anxiety and Hopelessness. The relationship between Intrinsic-value and Anxiety, negative in the full sample, is positive or zero in the classes. That last finding repeats itself for Utility -value: its relationship with Anxiety, negative in the full sample, has varied values in the classes.

\section{Prediction equations of activity emotions by proximal antecedents and class probabilities}

Large differences exist between overall level and class levels in relationships of proximal antecedents AcademicControl, Intrinsic and Utility-value, and activity emotions. To answer the third research question related to the context-dependency of activity emotions, Table SA12 (Statistical Appendix) contains standardized regression coefficients (betas) and explained variation for all constellations.

The strongest signal derived from this table stems from comparing the first two and last two panels. The explanatory power of the proximal antecedents of Anxiety and Boredom vanishes in a within-class analysis. With one exception, explained variation within classes is below four per cent. That is: inter-individual variation of Anxiety and Boredom is basically inter-class variation, with the intra-class variation being negligible. That is especially true for Boredom in ClassHigh and ClassLow: none of the proximal antecedents explains Boredom levels.

The lower two panels of Table SA12 tell a different story for Hopelessness and Enjoyment. Again, explained interclass variation still dominates explained intra-class variation, but intra-class variation explained by proximal antecedents is substantial, mostly between 10 and $20 \%$ of the total variation.

Another perspective on the relative magnitudes of interclass and inter-individual variation in activity emotions is based on regressing these emotions on latent class probabilities (taking Class3 as reference), on proximal antecedents, and the combination of latent class probabilities and proximal antecedents. Variation explained by class probabilities defines the inter-class variation. We compare that with the explained inter-individual variation based on proximal antecedents and variation explained by both class probabilities and proximal antecedents together. Table SA13 (Statistical Appendix) provides the outcomes of these regression models.
Class probabilities explain most of the variation in emotions Anxiety, Boredom, and Hopelessness: between 74 and 93\%; explained variation in Enjoyment is no more than 40\%. The variation explained by proximal antecedents alone is at a lower level. Therefore, adding proximal antecedents to class probabilities as explanatory factors of emotions has only a minor impact on explained variation. However, class probabilities and proximal antecedents share explained variation. For Boredom: adding proximal antecedents to class probabilities as predictors raises explained variation from 0.735 to 0.740 , whereas proximal antecedents themselves explain $21.1 \%$ of the variation in Boredom. This implies that $5 \%$ of the explained variation is unique, and $16.1 \%$ of the explained variation is shared.

Betas of class probabilities follow a fixed pattern. For Class1 and Class2, having fewer positive emotions than reference Class3, the beta for positive emotion is negative, the betas for negative emotions are positive. For Class 4 and Class5, with more positive emotions than Class3, the beta for positive emotion is positive, the betas for negative emotions are negative. ClassLow and ClassHigh are the exceptions to this pattern, with different signs for the beta of Boredom.

\section{Nonlinear prediction equations}

The fourth research question, the existence of potential under- and over-challenge effects in Boredom and other emotions, is investigated by applying regression models including squared and cubic terms of AcademicControl, after demeaning: see Table SA14 (Statistical Appendix). Although some of the nonlinear terms are significant, not in the Boredom equation. The largest effects are in the Anxiety equation, where a negative quadratic term decreases Anxiety levels at low and high AcademicControl levels, and a positive cubic term in the Hopelessness equation, that dampens the negative linear relationship at both ends. However, these effects are not practically significant: they increase $\mathrm{R}^{2}$ with at most $0.4 \%$.

\section{Distal antecedents of emotions: demographic factors and epistemic emotions}

As the last research question, the role of distal antecedents is investigated. Two distal antecedents, gender and mathematics prior education, demonstrate a strong relationship with the composition of the latent classes: see Fig. 6. Regarding gender composition, ClassLow (65\% female) and ClassHigh (18\% female) stand out. Percentage educated at an advanced track in high school, MathMajor, increases with higher levels of AcademicControl, with one exception: that percentage is lowest in ClassLow.

Table SA15 (Statistical Appendix) contains the direct effect of distal antecedents on activity emotions. Overall, 


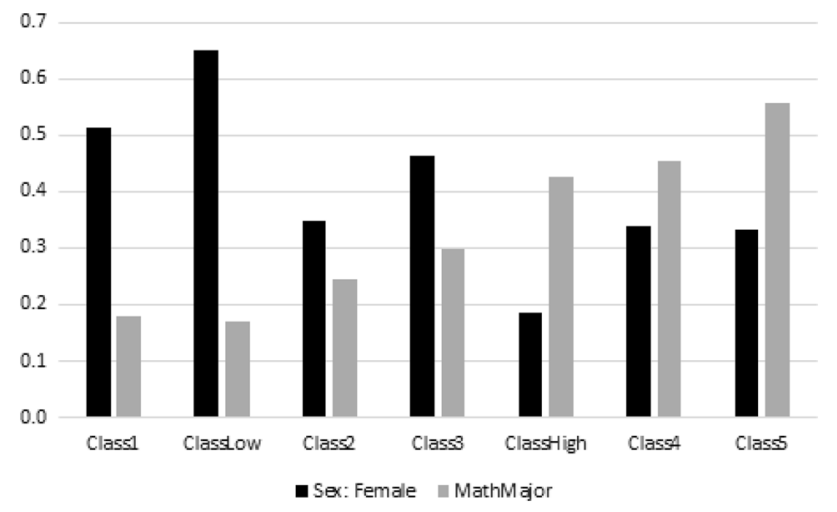

Fig. 6 Latent class composition: proportion of female students and proportion of MathMajor students

gender explains Anxiety (4.4\% explained variation, female students at higher levels), and prior education explains Anxiety (5.3\% explained variation) and Hopelessness (6.2\% explained variation) (MathMajor students at lower levels).

Gender and education effects differ by level of analysis. Prior education effects disappear in nearly all class-specific comparisons. The latent class composition with more MathMajor students in classes with higher levels of self-perceived control (see Fig. 6), equates emotion profiles of students of both types of prior education and thereby largely eliminates its role in explaining emotions at the class level. The case of gender is totally different. There are several constellations where the within-class gender difference exceeds the overall difference. Class1 with lowest levels of control is an example: it shows gender differences in Anxiety, Boredom, and Hopelessness that exceed overall gender differences. Here latent class decomposition does not 'neutralize' the gender effect.

Boredom scores exhibit Simpson's paradox: overall, students educated at an advanced level have lower Boredom levels than students educated at an intermediate level, but within six classes, it is the other way around: MathMajor students carry higher Boredom scores. These students are overrepresented in the classes with the lowest Boredom levels. There is no similar effect for Boredom gender differences: female students have lower levels, overall and in every class.

Epistemic emotions are the second distal antecedent, measured at the start of the module in the most recent six of ten cohorts. Together with gender and prior education, the seven epistemic emotions measures are applied as distal antecedents explaining activity emotions at the overall level (see Table SA16 (Statistical Appendix). The last row of that table signals that a substantial part of the variation in activity emotions is explained by distal antecedents present when the module starts. Three of the epistemic emotions correspond in object to one activity emotion: Anxious, Bored, and Excited, and act as prime predictors of activity emotions
Anxiety, Boredom, and Enjoyment. Hopelessness misses an epistemic emotion with the identical facet and finds main predictors in Anxious and Frustrated.

The role of gender and prior education is in line with earlier findings: Boredom has a strong gender effect but a small prior education effect, whereas other activity emotions contain both elements.

Comparing Table SA16 with Table SA12, the somewhat surprising message is that distal antecedents explain activity emotions better than proximal antecedents, at least for Anxiety, Boredom, and Enjoyment. The exception is Hopelessness, where AcademicControl dominates explanatory power of distal antecedents. Explanatory power at class level (Table SA18, Statistical Appendix) is lower than that at full sample level: the contribution of explained inter-class variation is lost. However, comparing this table with Table SA12 indicates this loss is smaller than when we explain activity emotions by proximal antecedents. AcademicControl and value facets explain, with one exception, no more than $4 \%$ of the variation of Anxiety and Boredom at the class level. Distal antecedents do better: their contribution to the explained variation ranges from $9.1 \%$ to $25.7 \%$. There is only one case where the proximal antecedents do better explain class-specific levels of activity emotions than distal antecedents: Hopelessness.

\section{Discussion}

\section{Types of boredom}

Applying experience sampling to investigate the relationships of the frequency of boredom observations with perceptions of valence and arousal, Goetz et al. (2014) decomposed the boredom construct in five types: four types of boredom that are linearly structured along the dimensions of low to high valence and arousal (indifferent, calibrating, searching, and reactant boredom), and one type, apathetic boredom, that falls outside this linear relationship. Apathetic boredom combines low arousal levels with high negative valence levels. Using a different research methodology and an intensity operationalization of boredom, we largely reproduce this outcome by finding seven latent classes of activity emotions: five that demonstrate a linear ordering and two classes falling outside the linear pattern, one with relative high boredom levels and the opposite case with low boredom relative to other constructs. The similarity in empirical outcomes of the Goetz et al. (2014) study and our study is especially remarkable, given the different operationalization of boredom: frequency measures versus intensity measures, and answers the first research question.

Our study finds one extra class in the linear ordered sequence. An explanation of this difference may be the size 
of our sample. Our Class 1 contains $4.7 \%$ of the full sample and may be missed in smaller samples. A second explanation might be our context: an achievement situation in which, depending on prior education, the full range from underchallenge to over-challenge is present, where the Goetz et al. (2014) study identifies mostly situations of under-challenge. The challenging nature of our module may explain another difference: the size of the high boredom class. In the university sample of the Goetz et al. (2014) study, $10 \%$ of students were in the Apathetic boredom class, against 5.5\% in our ClassHigh, the class with relatively high boredom levels. The strong achievement focus in our context may explain this: it is not easy to be bored and not anxious and hopeless at the same time when stakes are that high. Students may find themselves out of control but not out of value (Krannich et al., 2019).

Differences exist in the gender composition: in the Goetz et al. (2014) study, female students make two-third of the sample, against $40 \%$ in our study. That difference is important given that female students are underrepresented in ClassHigh, the class with relatively high levels of Boredom, and overrepresented in ClassLow, the class with relatively low levels of Boredom. The last difference is in the existence of ClassLow, be it that this is primarily a modelling choice: to cut off after seven classes rather than six.

\section{Inter-class and intra-class relationships}

Repeated measurement of learning emotions allows distinguishing inter-individual from intra-individual relationships: the second research question. These relationships are different in nature: due to the homogenization of predictor variables, intra-individual relationships are typically less articulated than inter-individual relationships. Lacking repeated measurements but profiting from a large, heterogeneous sample, we decomposed relationships in the full sample into inter-class relationships describing class means and intraclass relationships describing relations between students within classes. Figure 2 indicates inter-class relationships of emotions and academic control being strong, stronger than inter-individual relationships (as expected for relationships between group averages). Beyond ClassHigh and ClassLow, the classes with relatively high and low levels of Boredom respectively, acting as outliers, the other class means shape a perfect linear relationship. However, for Boredom, that is all that can be modelled: intra-class relations are basically absent. The overall relationship between academic control and boredom at the student level is fully determined by the linear ordering of latent class means. Within each class, Boredom is unrelated or weakly related to AcademicControl. The opposite case is Hopelessness. As with Boredom, it demonstrates a negatively sloped, linear pattern with AcademicControl for class means: see Fig. 2. To this adds a consistent, negative relationship between Hopelessness and AcademicControl within classes, correlations ranging from -0.29 to -0.41 : see Table SA10. Added together, these two effects produce a strong negative relationship, with correlation -0.69 , on student level.

\section{Emotion types as personality-specific dispositions}

Another outcome this study shares with Daniels et al. (2015) and Goetz et al. (2014) refers to our third research question's characterization of emotions types. Phrased with reservations in Goetz et al., (2014, p. 413), 'we can speculate that experiencing specific boredom types might, to some degree, be interpreted as being due to personality-specific dispositions,' our outcomes match up. The strongest signal comes from a comparison of proximal and distal antecedents. Activity emotions and proximal antecedents were measured halfway through the module within a particular problemsolving context. These are context-based, state-like measures. Distal antecedents are measured at module start with high school learning experiences as context, representing trait-like measures. Still, distal antecedents explain activity emotions better than proximal antecedents, except Hopelessness. That difference is large for within-class variation. The dominance of distal antecedents over proximal antecedents for Anxiety, Boredom, and Enjoyments implies that it is less the learning activity undertaken but more one's dispositions shaping the 'activity' emotions. This is the case for all emotions investigated except Hopelessness, for which it depends on the feeling of being in control, what is activity-specific and no disposition.

\section{Boredom and the lack of challenge and meaning hypothesis}

No support is found to characterize boredom as 'lack of challenge and meaning' (Pekrun et al., 2010; Van Tilburg \& Igou, 2012; Daniels et al., 2015; Krannich et al., 2019) at the overall level. If under-challenge and over-challenge produce Boredom, the topic of the fourth research question, the relationship between AcademicControl and Boredom were to be U-shaped curve-linear. We find curve-linear relationships in other emotions, but not Boredom. And the curvelinear effects, especially in Anxiety, are very weak. In the overall sample, Boredom is negatively related to AcademicControl, and Boredom levels are lower for students with an advanced level prior education, corresponding to an overchallenge mechanism. However, this effect shows up at the overall level only; within all classes, Boredom is unrelated to AcademicControl. In addition, we find that students educated at the advanced level have higher mean Boredom scores in six of seven classes. The Simpson paradox seems at work here: due to the overrepresentation of MathMajor 
students in the classes with low Boredom, no under-challenge effect is visible in the full sample, but it is present in the majority of classes.

\section{Gender and prior education as distal antecedents}

Given strong heterogeneity in prior education, it was expected that being educated at advanced levels would protect students against negative emotions and push positive ones: the fifth research question. But prior education effects are modest: associated with lower Hopelessness levels, but not with higher Enjoyment levels. Moreover, these modest prior education effects disappear in the latent classes. This suggests that the LCA-generated emotion profiles are congruent to patterns induced by education differences, even in ClassHigh and ClassLow.

As in Pekrun et al. (2010), male students encounter higher Boredom levels than female students. Relative to the valence of other emotions, this sets Boredom in a different position: male students tend to self-perceive negative emotions on lower levels while positive emotions and academic control on higher levels than female students. A remarkable difference with prior education is that the latent class decomposition does not absorb the gender effects.

\section{Limitation}

Although our application of latent class analysis took all four activity emotions into account, only Boredom indisputably exhibited the existence of a typology. Anxiety and Hopelessness obeyed the linear ordering, and only Enjoyment demonstrated some tendency toward a different type, be it weakly. This outcome is for certain limited to the conceptualization of activity emotions as in the AEQ instrument we applied. However, it coincides with the findings regarding the unique role of Boredom in a typology of learning activity emotions as established by Goetz et al., (2014, 2016), based on the different measurement framework of experience sampling applying different conceptualizations.

\section{Conclusions and implications for practice}

Boredom remains a complex emotional experience and a difficult to assess construct, mainly due to its salient nature requiring surveys or experience sampling approaches to provide insight. In this study, we sought to answer the question: can boredom and other learning activity emotions be adequately explained by variable-oriented models such as the CVTAE (Pekrun, 2006) suggest? Do different types of boredom exists, as suggested in Goetz et al., (2014, 2016)?

Boredom types exist, concluded the Goetz et al. (2014) study, and that is again the conclusion of our study. Although our operationalization of boredom is crucially different: frequency of expressions in the Goetz et al. (2014) study, intensity measures in our study. Starting from these different positions, both studies derive the existence of boredom types, monotonously ordered from positive to negative valence, from low to high arousal, from high to low academic control. Furthermore, both studies find a boredom type that escapes these compelling relationships: the apathetic boredom as described in the Goetz et al. (2014) study, the class with atypically high Boredom, low Enjoyment levels, relative to other emotions, AcademicControl, and Intrinsic-value in our study. This study adds the class with low Boredom but normal Enjoyment levels to this constellation, given AcademicControl and other emotions. The valence facet is dominant in the bivariate relationships of activity emotions, as visible in the full sample correlations. Valence differences largely determine the LCA classes: only the two extraordinary classes deviate from the strict linear ordering by valence level. Due to this composition of classes, the valence dimension loses its dominant role in the relationships of emotions at the class level, except for the extraordinary classes. At the class level, other features of emotions, like the activation nature, come to the forefront, as visible in the BoredomAnxiety relationships. Homogenization of the sample by LCA allowed seeing patterns that otherwise remained hidden behind other patterns.

The above conclusions suggest another: the existence of emotion types beyond boredom types. With the interpretation that emotions can be characterized in two types: more disposition-like, as a trait, or more context-dependent, as a state. We concluded that Boredom and Enjoyment are stronger disposition-based. Hopelessness seems to be stronger context-dependent, better explained by the learning context, and Anxiety takes a position in between. That difference in nature may help to interpret the outcomes of the latent class analysis. In essence, ClassHigh distinguishes from the other classes on Boredom and Enjoyment, but not on Anxiety and Hopelessness. The measurement of activity emotions was embedded in the context of several problemsolving tasks. This suggests that activity emotions differ how strong they depend on the specific learning activity, or are stronger disposition-based. From an educational perspective, this second typology is as important as the first one. If boredom is not only a silent, difficult to observe emotion, but also a relative invariant, difficult to address emotion, perspectives to intervene in boredom and enjoyment are minimal. Approaching more context-dependent emotions, such as hopelessness, might be more fruitful.

Another parallel to the Goetz et al. (2014) study refers to the issue of inter-personal versus intra-personal relationships. We transformed that comparison into one of the interclass and intra-class relationships. Although both these relationships are manifestations of interpersonal relations, there 
is a crucial difference. In essence, inter-class relationships represent relationships between different students with different emotion profiles. Intra-class relationships represent relations between different students with the same emotion profile. If we define a continuum from inter-personal to intra-personal relations, inter-class relations are positioned somewhere halfway (Howard \& Hoffman, 2018). Our study indicates that analyses producing substantial results at the inter-class and overall levels break down at the intra-class level: see the correlation between AcademicControl and Boredom. It is the exception rather than the rule that any relationship on inter-class level repeats itself at the intraclass level in an entirely consistent way. However, if most intra-class relations lack substance, significance, and consistency, one cannot expect intra-personal relations to be any stronger. This suggests that to the extent that CVTAE is meant to address processes at intra-individual level (Goetz et al., 2016), our outcomes are not encouraging.

The main implication is that the outcomes of the Goetz et al., $(2014,2016)$ studies appear being robust. Boredom types are not specific for experience sampling of the frequency of emotional sentiments but show up in cross-sectional observations of intensity and generalize to emotion types. That suggests strong evidence for the existence of emotion profiles, in which Boredom plays a special role: although the LCA is based on all activity emotions, it is primarily Boredom that stands out from the otherwise very dominant, valence based linear ordering. A second robust outcome of the Goetz et al., $(2014,2016)$ studies relates to CVTAE. Comparing inter-individual and intra-individual relationships between emotions and antecedents, these studies find relationships to differ, with in general intra-individual relationships being weaker than inter-individual ones. We obtain similar findings comparing inter-individual, interclass, and intra-class relationships. Inter-class relationships are stronger than inter-individual relationships (regression outcomes of means being stronger than regression outcomes of individual observations) and in line with CVTAE. Intraclass relationships are, however, weaker or absent. There are crucial differences between discrete activity emotions: for Hopelessness, most state-like and context-dependent, the intra-class relationships 'inherit' the inter-individual relationships. However, for the more trait-like emotion of Boredom, intra-class relationships based on CVTAE are weak or mostly absent. It is the combination of these replicated findings that brings the two main messages: we should be more attentive to checking the homogeneity condition in the first place. In case this condition does not satisfy, thereby telling that different profiles or types exist and each complies with different educational theories, we need to design more fine-grained theories that address inter-class relationships rather than intra-class relationships.
Supplementary Information The online version contains supplementary material available at https://doi.org/10.1007/s11031-021-09909-y.

Open Access This article is licensed under a Creative Commons Attribution 4.0 International License, which permits use, sharing, adaptation, distribution and reproduction in any medium or format, as long as you give appropriate credit to the original author(s) and the source, provide a link to the Creative Commons licence, and indicate if changes were made. The images or other third party material in this article are included in the article's Creative Commons licence, unless indicated otherwise in a credit line to the material. If material is not included in the article's Creative Commons licence and your intended use is not permitted by statutory regulation or exceeds the permitted use, you will need to obtain permission directly from the copyright holder. To view a copy of this licence, visit http://creativecommons.org/licenses/by/4.0/.

\section{References}

Buckingham Shum, S., \& Deakin Crick, R. (2012). Learning dispositions and transferable competencies: pedagogy, modelling and learning analytics. In S. Buckingham Shum, D. Gasevic, and R. Ferguson (Eds.), Proceedings of the 2nd International Conference on Learning Analytics and Knowledge (pp. 92-101). ACM, New York, NY, USA. https://doi.org/10.1145/2330601.2330629

Chan, C. S., van Tilburg, W. A. P., Igou, E. R., et al. (2018). Situational meaninglessness and state boredom: Cross-sectional and experience-sampling findings. Motivation \& Emotion, 42, 555-565. https://doi.org/10.1007/s11031-018-9693-3

Daniels, L. M., Tze, V. M. C., \& Goetz, T. (2015). Examining boredom: Different causes for different coping profiles. Learning and Individual Differences, 37, 255-261. https://doi.org/10.1016/j. lindif.2014.11.004

Eastwood, J. D., Frischen, A., Fenske, M. J., \& Smilek, D. (2012). The unengaged mind: Defining boredom in terms of attention. Perspectives on Psychological Science, 7(5), 482-495. https://doi. org/10.1177/1745691612456044

Elpidorou, A. (2020). Is boredom one or many? A functional solution to the problem of heterogeneity. Mind \& Language, $n / a(\mathrm{n} / \mathrm{a})$. https://doi.org/10.1111/mila.12282

Elpidorou, A. (2018a). The good of boredom. Philosophical Psychology, 31(3), 323-351. https://doi.org/10.1080/09515089.2017. 1346240

Elpidorou, A. (2018b). The bored mind is a guiding mind: Toward a regulatory theory of boredom. Phenomenology and the Cognitive Sciences, 17(3), 455-484. https://doi.org/10.1007/ s11097-017-9515-1

Fenichel, O. (1951). On the psychology of boredom. In D. Rapaport (Ed.), Organization and pathology of thought: Selected sources (pp. 349-361). New York, NY: Columbia University Press. https:// doi.org/10.1037/10584-018

Frenzel, A. C., Pekrun, R., \& Goetz, T. (2007). Perceived learning environment and students' emotional experiences: A multilevel analysis of mathematics classrooms. Learning and Instruction, 17(5), 478-493. https://doi.org/10.1016/j.learninstruc.2007.09.001

Goetz, T., Frenzel, A. C., Pekrun, R., \& Hall, N. C. (2006). The Domain Specificity of Academic Emotional Experiences. Journal of Experimental Education, 75(1), 5-29. eric. http://search.ebsco host.com/login. aspx ?direct $=$ true $\& \mathrm{db}=$ eric $\& A N=E J 773670 \&$ site $=$ ehost-live $\&$ scope $=$ site 
Goetz, T., \& Hall, N. C. (2014). Academic boredom. In International handbook of emotions in education (pp. 311-330). Routledge/ Taylor \& Francis Group.

Goetz, T., Hall, N. C., Krannich, M. (2019). Boredom. In K. Ann Renninger \& Suzanne E. Hidi, (Eds.), The cambridge handbook of motivation and learning (pp. 465-489). Cambridge: Cambridge University Press. htps://doi.org/https://doi.org/10.1017/97813 16823279.021

Goetz, T., \& Frenzel, A. C. (2006). Phänomenologie schulischer langeweile [Phenomenology of boredom at school]. Zeitschrift Für Entwicklungspsychologie Und Pädagogische Psychologie, 38(4), 149-153. https://doi.org/10.1026/0049-8637.38.4.149

Goetz, T., Frenzel, A. C., Hall, N. C., Nett, U. E., Pekrun, R., \& Lipnevich, A. A. (2014). Types of boredom: An experience sampling approach. Motivation and Emotion, 38(3), 401-419. https://doi. org/10.1007/s11031-013-9385-y

Goetz, T., Sticca, F., Pekrun, R., Murayama, K., \& Elliot, A. J. (2016). Intraindividual relations between achievement goals and discrete achievement emotions: An experience sampling approach. Learning and Instruction, 41, 115-125. https://doi. org/10.1016/j.learninstruc.2015.10.007

Howard, M. C., \& Hoffman, M. E. (2018). Variable-centered, personcentered, and person-specific approaches: Where theory meets the method. Organizational Research Methods, 21(4), 846-876. https://doi.org/10.1177/1094428117744021

Kline, R. B. (2016). Principles and practice of structural equation modeling (4th ed.). Guilford.

Krannich, M., Goetz, T., Lipnevich, A. A., Bieg, M., Roos, A., Becker, E. S., \& Morger, V. (2019). Being over- or underchallenged in class: Effects on students' career aspirations via academic self-concept and boredom. Learning \& Individual Differences, 69, 206-218. https://doi.org/10.5167/uzh-170991

Linnenbrink-Garcia L., Wormington S. V., Ranellucci J. (2016). Measuring affect in educational contexts: A circumplex approach. In M. Zembylas, P. Schutz (Eds.), Methodological advances in research on emotion and education (pp. 165-178). Springer, Cham. https://doi.org/10.1007/978-3-319-29049-2_13

Loukidou, L., Loan-Clarke, J., \& Daniels, K. (2009). Boredom in the workplace: More than monotonous tasks. International Journal of Management Reviews, 11(4), 381-405. https://doi.org/10. 1111/j.1468-2370.2009.00267.x

Marsh, H. W., Lüdtke, O., Trautwein, U., \& Morin, A. J. S. (2009). Classical latent profile analysis of academic self-concept dimensions: Synergy of person- and variable-centered approaches to theoretical models of self-concept. Structural Equation Modeling: A Multidisciplinary Journal, 16(2), 191-225. https://doi. org/10.1080/10705510902751010

Masyn, K. E. (2013). Latent class analysis and finite mixture modeling. In T. Little (Ed.), The oxford handbook of quantitative methods (Vol. 2, pp. 375-393). Oxford University Press.

Mercer, K. B., \& Eastwood, J. D. (2010). Is boredom associated with problem gambling behaviour? It depends on what you mean by 'boredom.' International Gambling Studies, 10(1), 91-104. https://doi.org/10.1080/14459791003754414

Mills, C., \& Christoff, K. (2018). Finding consistency in boredom by appreciating its instability. Trends in Cognitive Sciences, 22(9), 744-747. https://doi.org/10.1016/j.tics.2018.07.001

Molenaar, P. C. M. (2004). A manifesto on psychology as idiographic science: Bringing the person back into scientific psychology, this time forever. Measurement: Interdisciplinary Research and Perspectives, 2, 201-218.

Molenaar, P. C. M., \& Campbell, C. G. (2009). The new person-specific paradigm in psychology. Current Directions in Psychological Science, 18, 112-116. https://doi.org/10.1111/j.1467-8721. 2009.01619.x
Morin, A. J. (2016). Person-centered research strategies in commitment research. In J. P. Meyer (Ed.), The handbook of employee commitment (pp. 490-508). Edward Elgar.

Morin, A. J. S., Bujacz, A., \& Gagné, M. (2018). Person-Centered methodologies in the organizational sciences: introduction to the feature topic. Organizational Research Methods, 21(4), 803-813. https://doi.org/10.1177/1094428118773856

Murayama, K., Goetz, T., Malmberg, L-E., Pekrun, R., Tanaka, A., \& Martin, A. J. (2017). Within-person analysis in educational psychology: Importance and illustrations. British Journal of Educational Psychology Monograph Series II: Psychological Aspects of Education-Current Trends: The Role of Competence Beliefs in Teaching and Learning. In D. W. Putwain \& K. Smart (Eds.), 12 (pp. 71-87). Oxford: Wiley.

Niculescu, A. C., Tempelaar, D., Dailey-Hebert, A., Segers, M., \& Gijselaers, W. (2015). Exploring the antecedents of learningrelated emotions and their relations with achievement outcomes. Frontline Learning Research, 3(1), 1-16. http://journals.sfu.ca/ flr/flr/index.php/journal/article/view/136

Ohsuga, M., Shimono, F., \& Genno, H. (2001). Assessment of phasic work stress using autonomic indices. International Journal of Psychophysiology, 40(3), 211-220. https://doi.org/10.1016/ S0167-8760(00)00189-6

Pekrun, R. (2000). A social-cognitive, control-value theory of achievement emotions. In J. Heckhausen (Ed.), Motivational psychology of human development: Developing motivation and motivating development (pp. 143-163). Elsevier Science.

Pekrun, R. (2006). The control-value theory of achievement emotions: assumptions, corollaries, and implications for educational research and practice. Educational Psychology Review, 18(4), 315-341. https://doi.org/10.1007/s10648-006-9029-9

Pekrun, R. (2012). Emotion regulation. In N. Seel (Ed.), Encyclopedia of the Sciences of Learning. New York: Springer.

Pekrun, R., Goetz, T., Daniels, L. M., Stupnisky, R. H., \& Perry, R. P. (2010). Boredom in achievement settings: Exploring controlvalue antecedents and performance outcomes of a neglected emotion. Journal of Educational Psychology, 102(3), 531-549. https://doi. org/10.1037/a0019243

Pekrun, R., Goetz, T., Frenzel, A. C., Barchfeld, P., \& Perry, R. P. (2011). Measuring emotions in students' learning and performance: The achievement emotions questionnaire (AEQ). Contemporary Educational Psychology, 36(1), 36-48. https://doi.org/ 10.1016/j.cedpsych.2010.10.002

Pekrun, R., Goetz, T., Titz, W., \& Perry. R. P. (2002). Academic emotions in students' self-regulated learning and achievement: A program of qualitative and qantitative research. Educational Psychologist, 37(2), 91-105. https://doi.org/10.1207/S15326985E P3702_4

Pekrun, R., Vogl, E., Muis, K. R., \& Sinatra, G. M. (2017). Measuring emotions during epistemic activities: The epistemically-related emotion scales. Cognition and Emotion, 31(6), 1268-1276. https://doi.org/10.1080/02699931.2016.1204989

Perry, R. P., Hladkyj, S., Pekrun, R. H., \& Pelletier, S. T. (2001). Academic control and action control in the achievement of college students: A longitudinal field study. Journal of Educational Psychology, 93(4), 776-789. https://doi.org/10.1037/0022-0663.93.4.776

Schwartze, M. M., Frenzel, A. C., Goetz, T., Pekrun, R., Reck, C., Marx, A. K. G., \& Fiedler, D. (2021). Boredom makes me sick: Adolescents' boredom trajectories and their health-related quality of life. International Journal of Environmental Research and Public Health, 18(12), 6308. https://doi.org/10.3390/ijerph18126308

Tempelaar, D. T., Gijselaers, W. H., Schim van der Loeff, S., \& Nijhuis, J. F. H. (2007). A structural equation model analyzing the relationship of student achievement motivations and personality factors in a range of academic subject-matter areas. Contemporary 
Educational Psychology, 32(1), 105-131. https://doi.org/10. 1016/j.cedpsych.2006.10.004

Tempelaar, D., Rienties, B., \& Giesbers, B. (2015). In search for the most informative data for feedback generation: Learning analytics in a data-rich context. Computers in Human Behavior, 47, 157-167. https://doi.org/10.1016/j.chb.2014.05.038

Tempelaar, D., Rienties, B., Mittelmeier, J., \& Nguyen, Q. (2018). Student profiling in a dispositional learning analytics application using formative assessment. Computers in Human Behavior, 78, 408-420. https://doi.org/10.1016/j.chb.2017.08.010

van Hooft, E. A. J., \& van Hooff, M. L. M. (2018). The state of boredom: Frustrating or depressing? Motivation and Emotion, 42(6), 931-946. https://doi.org/10.1007/s11031-018-9710-6

van Tilburg, W. A. P., \& Igou, E. R. (2012). On boredom: Lack of challenge and meaning as distinct boredom experiences. Motivation and Emotion, 36(2), 181-194. https://doi.org/10.1007/ s11031-011-9234-9

van Tilburg, W. A. P., \& Igou, E. R. (2016). Boredom begs to differ: Differentiation from other negative emotions. Emotion, 17(2), 309. https://doi.org/10.1037/emo0000233

Voelkle, M. C., Brose, A., Schmiedek, F., \& Lindenberger, U. (2014). Toward a unified framework for the study of between-person and within-person structures: building a bridge between two research paradigms. Multivariate Behavioral Research, 49(3), 193-213. https://doi.org/10.1080/00273171.2014.889593

Vogl, E., Pekrun, R., Murayama, K., \& Loderer, K. (2019, March 18). Surprised-Curious-Confused: Epistemic emotions and knowledge exploration. Emotion. Advance online publication. https://doi.org/ 10.1037/emo0000578

Westgate, E. C., \& Wilson, T. D. (2018). Boring thoughts and bored minds: The MAC model of boredom and cognitive engagement. Psychological Review, 125(5), 689. https://doi.org/10.1037/rev00 00097

Weybright, E. H., Schulenberg, J., \& Caldwell, L. L. (2020). More bored today than yesterday? National trends in adolescent boredom from 2008 to 2017. Journal of Adolescent Health, 66(3), 360-365. https://doi.org/10.1016/j.jadohealth.2019.09.021

Wigfield, A., \& Eccles, J. S. (2000). Expectancy - value theory of achievement motivation. Contemporary Educational Psychology, 25, 68-81. https://doi.org/10.1006/ceps.1999.1015

Williams, A., Sun, Z., Xie, K., Garcia, E., Ashby, I., Exter, M., Largent, D., Lu, P., Szafron, D., Ahmed, S., Onuczko, T., Smith, J., Tempelaar, D. T., Bitting, K. S., Olcott Marshall, A., Christensen, E., Tseng, H., \& Walsh, J. (2016). Flipping STEM. In L. Santos Green, J. Banas, R. Perkins (Eds.), The flipped college classroom, conceptualized and re-conceptualized, Part II (pp. 149-186). Switzerland: Springer International Publishing.

Publisher's Note Springer Nature remains neutral with regard to jurisdictional claims in published maps and institutional affiliations. 